\title{
Percepções de licenciandos(as) em Ciências Biológicas acerca da disciplina Didática e sua contribuição para a formação de professores
}

\author{
Perceptions of undergraduate students in Biological Sciences about the Didactics discipline and its \\ contribution to teacher education
}

Percepciones de los estudiantes de grado en Ciencias Biológicas sobre la disciplina Didáctica y su contribución a la formación del profesorado

\author{
Leandro dos Anjos Costa \\ ORCID: https://orcid.org/0000-0001-5287-5974 \\ Instituto Federal de Educação, Ciência e Tecnologia do Piauí, Brasil \\ E-mail: leandro.costa94@ hotmail.com \\ Ícaro Fillipe de Araújo Castro \\ ORCID: https://orcid.org/0000-0003-1808-9157 \\ Instituto Federal de Educação, Ciência e Tecnologia do Piauí, Brasil \\ E-mail: icaro.castro@ifpi.edu.br \\ Mayara Danyelle Rodrigues de Oliveira \\ ORCID: https://orcid.org/0000-0001-6443-5976 \\ Instituto Federal de Educação, Ciência e Tecnologia do Piauí, Brasil \\ E-mail: mayara.oliveira@ifpi.edu.br
}

\begin{abstract}
Resumo
A Didática é considerada indispensável à formação de professores, e as perspectivas de discentes relacionadas à disciplina podem apontar caminhos fundamentais para seu constante aprimoramento. Dessa forma, esse trabalho teve como objetivo conhecer as percepções de Licenciandos em Ciências Biológicas relacionadas à disciplina Didática e sua importância para a formação docente em uma Instituição de Ensino Superior situada no município de Uruçuí-PI. A pesquisa é do tipo quali-quantitativa, e possui natureza observacional. Para sua realização, contou com a participação de 28 discentes que cursavam a partir do sexto período. A partir das análises das respostas dos participantes, observou-se que a principal expectativa dos alunos em relação à disciplina era de conhecer novas metodologias para guiá-los em sala de aula, e que a maior parte do grupo amostral veem a disciplina como fundamental para sua formação. Em relação as habilidades adquiridas ao cursar Didática, a mais mencionada foi a capacidade de elaborar e aplicar planos de ensino, observando seus elementos constitutivos. Foi também verificada dificuldade para refletir as estratégias diversificadas de avaliação de aprendizagem. Diante dos resultados apresentados neste estudo, apontamos que muitos estudantes entram nos cursos de licenciaturas por falta de oportunidade em ingressar em outro curso desejado, que tem como principal motivo o cenário educacional brasileiro, onde os professores são desvalorizados, desassistidos e desrespeitados. Sendo fundamental a valorização dos profissionais para a qualidade do ensino. Por fim, relatamos que a maior motivação dos graduandos em cursar a disciplina Didática foi a de conhecer novas metodologias para serem utilizadas em sala de aula no seu fazer docente. Dessa forma, é importante se aproveitar desse interesse e motivação dos discentes, e a partir dele apresentar e estimular o uso de metodologias diversas no contexto escolar, que permitam assim maior suporte ao docente em formação, para que esteja preparado para a diversidade de discentes que encontrará em sala de aula. Apontamos também a necessidade de realização de outros estudos, inclusive com professores que atuam na educação básica, avaliando também a importância da disciplina no contexto escolar desses docentes.
\end{abstract}

Palavras-chave: Formação docente; Disciplinas pedagógicas; Ensino-aprendizagem.

\begin{abstract}
Didactic is considered essential for the training of teachers and as perspectives of disciplines related to the discipline can highlight paths for its constant improvement. Thus, this work aimed to understand the perceptions of Undergraduates in Biological Sciences related to the Didactics discipline and its importance for teacher education in Higher Education Institution located in the city of Uruçuí-PI. The research is of the quali-quantitative type, it has an observational nature. For its realization, it had the participation of 28 students who attended from the sixth period. From the analysis of the participants' responses, it was observed that the main expectation of students in relation to the subject was to know new methodologies to guide them in the classroom, and that most of the sample group see the subject as fundamental for their training. Regarding the skills acquired while studying Didactics, the most mentioned for the ability to prepare and apply teaching plans, observing their constituent elements. Difficulty to reflect the
\end{abstract}


diversified learning assessment strategies was also verified. Given the results obtained in this study, we point out that many students enter teaching courses for lack of opportunity to enter another desired course, whose main reason is the Brazilian educational scenario, where teachers are undervalued, neglected and disrespected. It is essential to value professionals for the quality of teaching. Finally, we report that a greater motivation of undergraduates in the course and Didactic discipline was to learn about new methodologies to be used in the classroom in their teaching practice. Thus, it is important to take advantage of this interest and motivation of students, and from it to present and encourage the use of different methodologies in the school context, which will thus provide greater support to the teacher in training, so that they are prepared for the diversity of students who arrive in the classroom. We also specify the need for further studies, including teachers who work in basic achievement education, also evaluate the importance of the discipline in the school context of these teachers.

Keywords: Teaching initiation; Pedagogical subjects; Teaching-learning.

\section{Resumen}

La didáctica se considera fundamental para la formación de los docentes y como perspectivas de disciplinas afines a la disciplina se pueden señalar caminos para su mejora constante. Así, este trabajo tuvo como objetivo comprender las percepciones de los Licenciados en Ciencias Biológicas relacionadas con la disciplina Didáctica y su importancia para la formación docente en una Institución de Educación Superior ubicada en la ciudad de Uruçuí-PI. La investigación es de tipo cuali-cuantitativo, tiene un carácter observacional. Para su realización contó con la participación de 28 alumnos que asistieron del sexto período. A partir del análisis de las respuestas de los participantes, se observó que la principal expectativa de los estudiantes en relación a la asignatura era conocer nuevas metodologías para orientarlos en el aula, y que la mayoría del grupo de la muestra ve la asignatura como fundamental para su formación. En cuanto a las competencias adquiridas durante el estudio de Didáctica, las más mencionadas por la capacidad de elaborar y aplicar planes de enseñanza, observando sus elementos constitutivos. También se verificó la dificultad para reflejar las estrategias de evaluación de aprendizaje diversificadas. Dados los resultados obtenidos en este estudio, señalamos que muchos estudiantes ingresan a cursos de docencia por falta de oportunidad de ingresar a otro curso deseado, cuya principal razón es el escenario educativo brasileño, donde los docentes son infravalorados, desatendidos y menospreciados. Es fundamental valorar a los profesionales por la calidad de la docencia. Finalmente, informamos que una mayor motivación de los estudiantes de la carrera y disciplina de Didáctica fue conocer nuevas metodologías para ser utilizadas en el aula en su práctica docente. Por ello, es importante aprovechar este interés y motivación de los estudiantes, y a partir de él presentar y fomentar el uso de diferentes metodologías en el contexto escolar, que asî brindarán un mayor apoyo al docente en formación, para que esté preparado. por la diversidad de alumnos que llegan al aula. También señalamos la necesidad de realizar más estudios, incluso con docentes que trabajan en educación de rendimiento básico, evaluando también la importancia de la disciplina en el contexto escolar de estos docentes.

Palabras clave: Formación de profesores; Asignaturas pedagógicas; Enseñanza-aprendizaje.

\section{Introdução}

As disciplinas pedagógicas fazem parte das matrizes curriculares dos cursos de licenciatura que trabalham com os aspectos eminentemente pedagógicos, seguindo os elementos característicos do processo de ensino e aprendizagem, como os conteúdos programáticos, estratégias, metodologias de ensino e avaliação (Ribeiro et al., 2017). Dessa forma, percebemos que as disciplinas pedagógicas têm protagonismo no processo de formação de professores, pois permitem um aprimoramento das metodologias de ensino, além de apresentarem aos futuros docentes novas perspectivas e tendências educacionais ${ }^{1}$.

Seguindo essa perspectiva, Batista et al. (2018) afirmam que as disciplinas pedagógicas têm como finalidade fomentar a reflexão entre teoria e prática e, dessa maneira, subsidiar a ação que requer do professor formador. Dessa forma, as disciplinas pedagógicas se mostram eficazes para a reflexão do professor, capacitando-o à prática docente e levando-o a pensar em novas maneiras de ensinar.

Para Henrique e Nascimento (2015), os professores são diariamente estimulados em relação às práticas pedagógicas que objetivem a integração ou o diálogo entre diferentes disciplinas, cursos, áreas de conhecimento e instituições. Podemos assim entender que as disciplinas pedagógicas aplicadas ao contexto da educação básica, permitem ao docente relacionar conhecimentos importantes do currículo escolar, estimulando-o à interdisciplinaridade. Dentre as diversas disciplinas comumente apresentadas nos cursos de Licenciatura, destacamos a Didática como sendo muito importante no auxílio à

${ }^{1}$ As tendências educacionais ou pedagógicas são um conjunto de pensamentos de filósofos e autores que falam de como educação é compartilhada. Existem dois modelos: o liberal e o progressista. Enquanto o primeiro quer manter a sociedade do jeito que ela está, o segundo coloca a educação como ferramenta transformadora na nossa sociedade. 
formação dos docentes, uma vez que possui caráter preparatório na utilização de ferramentas pedagógicas em sala de aula, contribuindo diretamente para o processo de ensino e aprendizagem do aluno, bem como estimulando a reflexão dos licenciandos sobre a profissão docente.

Para Libâneo (2017), o alvo de estudo da Didática é o desenvolvimento de ensino e aprendizagem. Essa disciplina deve ser caracterizada pela mediação entre as bases teórico-científicas da educação escolar e a prática docente. Seguindo essa perspectiva, Trez (2016), afirma que observar a proposta do futuro professor em Didática ainda durante o período da graduação será de extrema importância para a reflexão a respeito do desempenho destes docentes em sala de aula.

De acordo com Gonçalves e Rochael (2015), a Didática poderá ser aproveitada como instrumento facilitador, visto que a mesma contribuirá com o professor na condução e orientação do processo de ensino e aprendizagem. Bastos (2017) acrescenta que a Didática é uma ciência indispensável que se empenha a empregar de maneira correta suas técnicas de ensino, objetivando incentivar nos discentes o desejo de aprender e o estímulo ao pensamento crítico, criatividade e formação para o pleno exercício da cidadania.

Apesar da importância da Didática e de outras disciplinas de caráter pedagógico, Batista et al. (2018) apontam que somente uma pequena parcela dos licenciandos consideram que essas disciplinas irão prepará-los para atuar em sala de aula, e que é mais importante focar nos componentes curriculares específicos da área, visto que, para a maioria dos estudantes, somente estes irão sustentá-los na sua atuação docente. Para Silva (2019), a Didática se insere no principal ramo de estudos da Pedagogia, uma vez que é preciso dominar todas as teorias para que haja uma prática educativa satisfatória; dessa forma, o professor se apropria de recursos teóricos para a organização e articulação no processo de ensino e aprendizagem.

Embora a disciplina de Didática não apresente um modelo pronto de como ministrar boas aulas, é caracterizada como uma maneira de reflexão às formas e modelos de se trabalhar em sala de aula. Frente à importância da mesma na formação docente, pesquisas que busquem conhecer as perspectivas de discentes relacionadas à disciplina Didática e sua condução no ensino superior são importantes ferramentas diagnósticas que permitem apontar falhas e virtudes, em busca de seu constante aprimoramento. Dessa forma, essa pesquisa teve como objetivo conhecer as percepções de Licenciandos em Ciências Biológicas de uma Instituição Federal de Ensino relacionadas à disciplina Didática e sua importância para a formação de professores na perspectiva dos participantes.

\section{Metodologia}

A referida pesquisa é exploratória quanto aos seus objetivos, uma vez que visa inicialmente maior aproximação do pesquisador com o tema, para familiarizá-lo com os fatos e fenômenos relacionados ao problema. Quanto a abordagem, é quali-quantitativo, visto que os resultados se baseiam na quantidade de respostas e além disso, requerem a opinião e interpretação do pesquisador no que diz respeito à temática (Ludke \& Andre, 2013). Quanto à finalidade, se caracteriza como básica e possui natureza observacional. Em relação aos procedimentos técnicos adotados para esse estudo, apontamos a pesquisa documental e de campo (Fontelles et al., 2009).

Inicialmente, foi realizada uma análise do Projeto Pedagógico do Curso (PPC) de Licenciatura em Ciências Biológicas da instituição de ensino onde ocorreu a pesquisa; tal análise foi fundamental para a elaboração do questionário aplicado aos discentes, com ênfase aos objetivos, habilidades e competências propostas pela disciplina. Além disso, foram analisados pontos positivos e negativos relacionados à construção do PPC, bem como a observância das contribuições da disciplina Didática na formação desses futuros professores.

Em seguida, confeccionou-se um questionário semi-estruturado, no qual foram abordados alguns elementos relacionados à disciplina Didática, sendo tais questões orientadas pelos objetivos, habilidades e competências para a disciplina, presentes no PPC. Para a participação na pesquisa, os licenciandos tiveram que assinar um Termo de Consentimento Livre e 
Esclarecido (TCLE), que entre outras coisas garantia o anonimato ao participante, e retirada da pesquisa a qualquer momento anterior a publicação. Todos os Licenciandos em Ciências Biológicas convidados a participar da pesquisa cursavam a partir do sexto módulo no momento de aplicação do questionário, uma vez que a disciplina Didática é ofertada no quinto período do referido curso.

Com o propósito de garantir a segurança dos pesquisadores e participantes, tendo em vista a pandemia da COVID-19 e as recomendações da Organização Mundial da Saúde (OMS), o convite à pesquisa ocorreu de forma virtual, por intermédio da ferramenta de comunicação WhatsApp, e os esclarecimentos sobre a pesquisa e coleta de dados junto aos discentes ocorreram por meio da ferramenta digital Google Forms; tal ferramenta é gratuita e disponibilizada pelo site Google desde 2012. De acordo com Mota (2019), ela comporta uma diversidade de possibilidades para uso acadêmico ainda não vistas em outras ferramentas digitais, como obtenção de respostas imediatas e organizadas em forma de gráficos e tabelas que facilitam sistematicamente a interpretação de pesquisas realizadas pela plataforma.

O questionário criado na plataforma continha um total de 12 questões obrigatórias de múltipla escolha e uma questão aberta. A primeira seção do questionário correspondia ao TCLE e a segunda seção foi composta por perguntas relacionadas ao perfil dos (as) participantes, como gênero, idade e período que estão cursando. A terceira seção trazia questões relacionadas ao "ser professor", e a última seção foi composta por perguntas relacionadas à disciplina de Didática no curso de Licenciatura em Ciências Biológicas. Após a coleta das respostas, os dados foram computados e tabulados em forma de gráficos e tabelas, utilizando-se para isso a ferramenta Excel (2007). Para a questão descritiva, realizou-se uma análise de conteudo, baseada em Ferreira e Loguecio (2014), que tinha como objetivo à manipulação das respostas discussivas apresentadas pelos participantes para interpretação e inferência dos sentidos.

\section{Resultados e Discussão}

Participaram da pesquisa um total de 28 discentes, dos quais 20 participantes $(71,4 \%)$ pertenciam ao gênero feminino, sete participantes $(25 \%)$ pertenciam ao gênero masculino e um participante (3,6 \%) preferiu não identificar o gênero. Em relação à idade, a faixa etária predominante foi de alunos que tinham entre 21 e 23 anos $(60,7 \%)$. A amostra foi composta por alunos do sétimo período (32,1\%) e nono período $(67,9 \%)$ do curso de Licenciatura em Ciências Biológicas, uma vez que a instituição de ensino escolhida só abre turmas anualmente.

$\mathrm{Na}$ primeira questão, foi perguntado aos participantes sobre o motivo pela escolha do curso de Licenciatura em Ciências Biológicas. Nas respostas, a maioria dos participantes (13 - 46,4 \%) apontou que a escolha ocorreu por não conseguir ingressar no curso desejado, 11 participantes $(39,3 \%)$ justificaram sua escolha pela afinidade com as Ciências Biológicas, três participantes $(10,7 \%)$ relataram que se identificam com a profissão docente, e um participante $(3,6 \%)$ escolheu o curso por incentivo de familiares e amigos, como observado na Figura 1. 
Figura 1 - Justificativa dos discentes acerca da escolha pelo curso de Licenciatura em Ciências Biológicas.

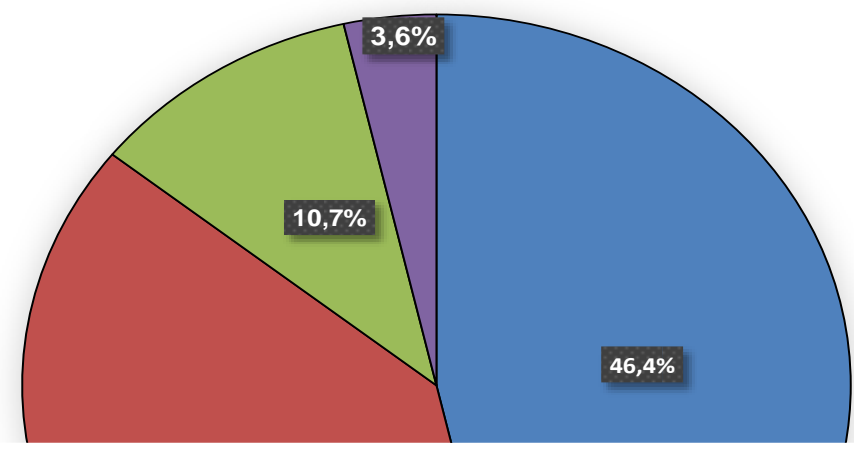

Fonte: Autores (2021).

Para Milam (2017), ao concorrer a uma vaga em um curso superior, muitos estudantes que terminam o ensino médio em escolas públicas optam por cursos que possuem menor concorrência, tais como os cursos de Licenciatura, em comparação aos cursos de maior concorrência. Além disso, muitos não se sentem capacitados o suficiente para concorrerem aos cursos mais disputados de uma universidade. Tal pensamento exprime a realidade, porque os cursos de licenciatura ainda são alguns dos menos concorridos nas universidades, mas será que realmente é possível mudarmos essa cultura? Acreditamos que uma maior valorização do professorado, principalmente os de rede pública nos âmbitos municipal e estadual, poderá atrair mais pessoas para concorrer aos cursos em questão.

$\mathrm{Na}$ segunda questão, os participantes foram indagados sobre à vontade em ser docente no início do curso em comparação ao momento atual. Nas respostas, a maior parte dos participantes (doze - 42,9 \%) afirmam que entraram sem querer ser professor, mas que agora desejam seguir a carreira docente; em contrapartida, nove participantes (32,1 \%) responderam que não sabem ao certo o que realmente querem. Seis $(21,4 \%)$, por sua vez, afirmaram que entraram no curso querendo ser professores e permanecem com a vontade de serem docentes. Entretanto, um participante (3,6 \%) respondeu que entrou no curso desejando seguir na docência, porém atualmente não quer seguir carreira, como demonstrado na Figura 2.

Figura 2 - Interesse dos graduandos em seguirem a profissão docente no início do curso e atualmente.

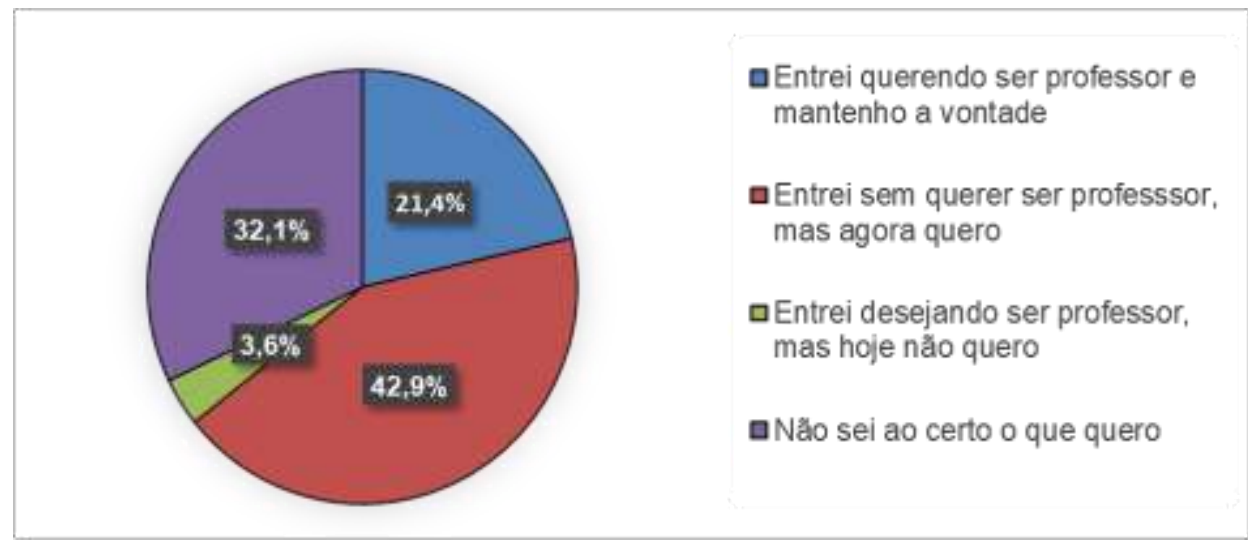

Fonte: Autores (2021).

De acordo com Cerqueira e Cardoso (2010), muitos estudantes ficam confusos antes e durante o exercício da profissão e, bem antes de se identificarem como professores, passam pelo estágio de reconhecimento pessoal até se definirem profissionalmente; as mesmas autoras ainda falam que, para se alcançar a uma boa prática em sala de aula, é necessário adquirir uma boa formação. Analisando os dados da Figura 2, e comparando-os com o estudo de Cerqueira e Cardoso (2010), é possível observar que muitos alunos passam por um momento de dúvida em relação à escolha da profissão; entretanto, outros 
alunos, por sua vez, nem mesmo possuem a oportunidade de escolher o curso almejado, pois pleiteiam os cursos que estão disponíveis em sua região ou condizentes com sua nota. Tal situação é deveras negativa, tendo em vista que os discentes não estão se formando na profissão que inicialmente gostariam, e que alguns até desistem por não se encaixarem na profissão; entretanto, pode-se encontrar positividade no fato de muitos se descobrirem na profissão à medida em que obtém experiência durante a graduação.

Simão e Reali (2002), por sua vez, afirmam que os professores necessitam estar aptos a preparar cidadãos participantes da sociedade da informação, que requer um novo perfil de profissional, "[...] um indivíduo crítico, criativo, com capacidade de pensar, de aprender de forma contínua, de trabalhar em grupo, de utilizar os meios automáticos de produção e disseminação da informação e de conhecer o seu potencial cognitivo, afetivo e social". Nesse contexto, é importante refletir se as universidades estão realmente formando profissionais com esse perfil para atuarem na docência, principalmente devido ao fato de muitos estudantes ingressam nas universidades e não cursarem a graduação almejada, e sim para cursar aquela compatível com a nota que obtiveram no processo seletivo, uma vez que os cursos de licenciatura possuem as menores concorrências por vagas nos vestibulares (Fernandes et al., 2016).

Posteriormente, foi indagado aos discentes acerca das principais dificuldades que os mesmos poderiam vivenciar em sala de aula no exercício da profissão docente. A maioria (10 participantes - 35,6\%) afirmaram que a principal dificuldade é manter a disciplina dos alunos; oito participantes $(28,6 \%)$, por sua vez, responderam que ainda não percebem possíveis dificuldades na profissão. Quatro graduandos $(14,3 \%)$ responderam que a sua principal dificuldade seria aplicar os conhecimentos específicos aprendidos no curso; para outros quatro discentes $(14,3 \%)$, a principal dificuldade seria se adequar à rigidez dos currículos escolares. Para um participante $(3,6 \%)$, a principal dificuldade seria aplicar os conhecimentos pedagógicos aprendidos no curso; e um participante (3,6 \%) respondeu que não pretende exercer a profissão docente, como demonstrado na Figura 3.

Figura 3 - Dificuldades que os mesmos poderão vivenciar em sala de aula, caso exerça a profissão.

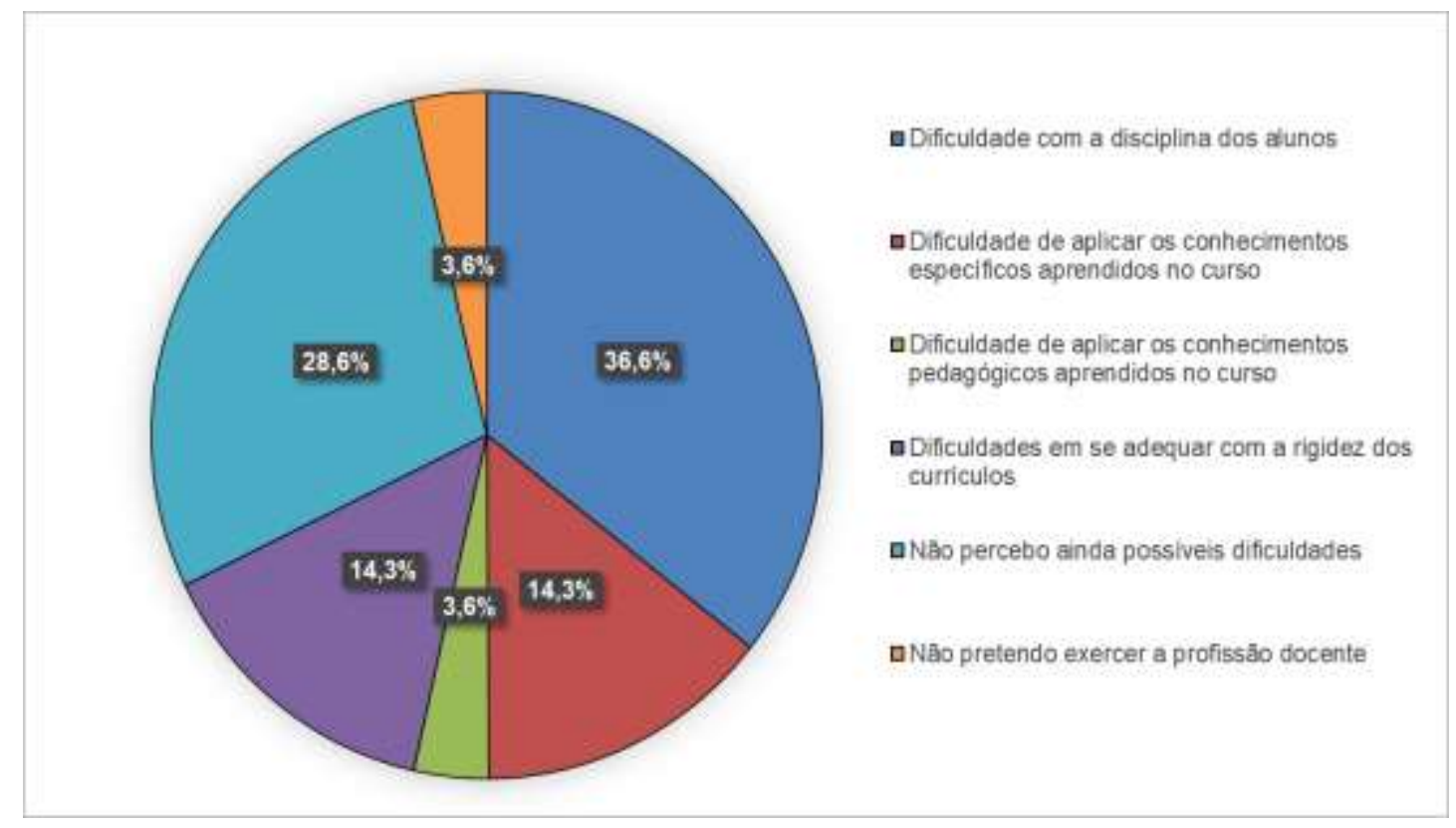

Fonte: Autores (2021).

Analisando esse contexto de dificuldades enfrentadas pelo professor em sala de aula, Faustino et al., (2013) destacam que muitos docentes desistem da profissão, por não atingirem as perspectivas da educação moderna, bem como pela dificuldade de disciplina pelos discentes, frustrando dessa forma as tentativas para a adequação dos mesmos ao processo de ensino. Nesse sentido, nota-se a importância da preparação docente em diversos conhecimentos para exercer a profissão, pois a 
mesma requer atualizações, empenho e planejamento; além disso, nem sempre a realidade que os futuros professores enfrentam durante a etapa de estágio na graduação, por exemplo, será a mesma que encontrarão quando estiverem atuando na profissão.

Na quarta questão, indagou-se aos discentes qual a importância da disciplina Didática em si para a formação docente dos mesmos. A maior parte dos participantes, 21 indivíduos $(77,8 \%)$, responderam que a disciplina foi muito importante e que aprendeu muito com ela. Entretanto, seis participantes $(22,2 \%)$ responderam que a disciplina Didática foi pouco importante para a sua formação. Nenhum dos participantes considerou a disciplina como sem importância, como observado na Figura 4.

Figura 4 - Respostas dos participantes da pesquisa acerca da importância da disciplina Didática para a formação docente.

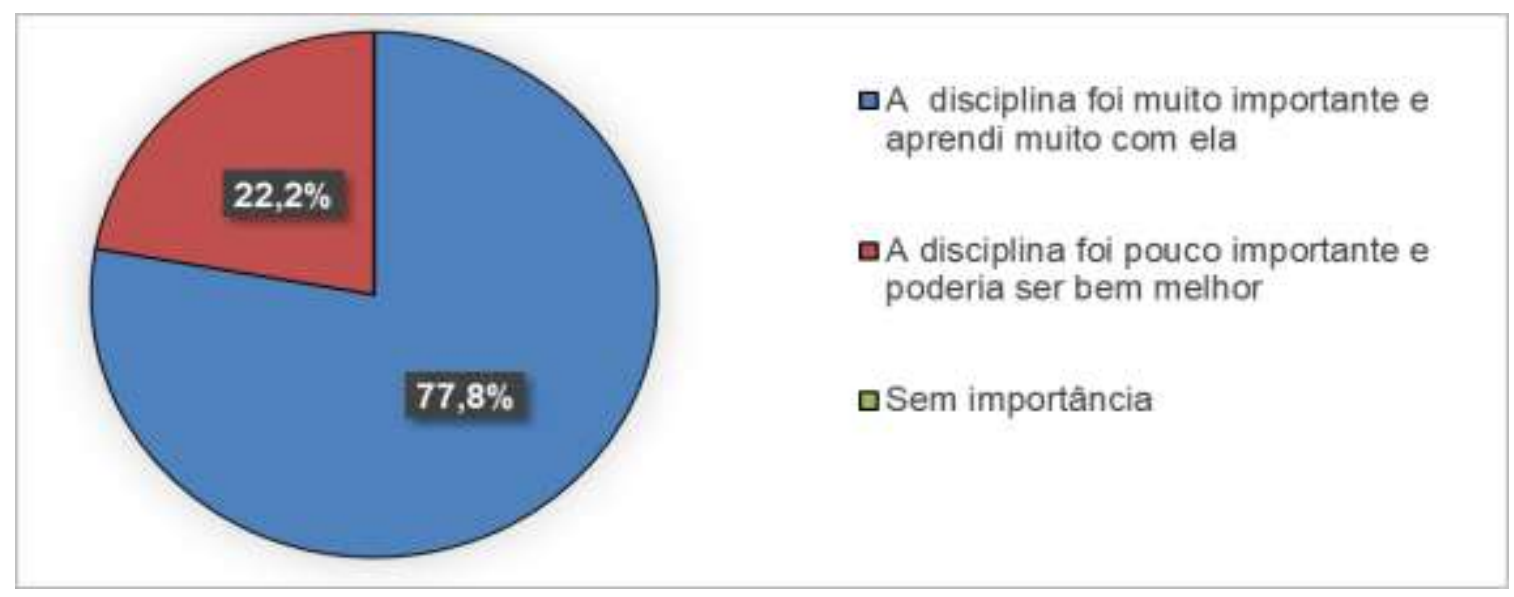

Fonte: Autores (2021).

A Didática é uma disciplina norteadora teórica/científica, indispensável à atividade pedagógica do dia a dia, pois sinaliza a eficiência do processo de ensino-aprendizagem (Bastos, 2017). Segundo Ribeiro et al. (2018), a mesma é fundamental na elaboração de novas maneiras de ensino, visto que provoca uma mudança da teoria à prática pedagógica, ou seja, faz uma relação da teoria com a prática; ele ainda ressalta que a aplicação da disciplina Didática de maneira eficiente proporciona um alcance dos objetivos previamente estabelecidos para o ensino.

Dessa maneira, podemos entender a Didática como uma disciplina que ajuda no planejamento docente, visto que a mesma oferece um caminho pré-estabelecido, para assim guiar os futuros docentes. Nesse sentido, Silva (2019) afirma que a disciplina alicerça a ação do professor, considerando-se que é por meio dela que a teoria e a prática se fortalecem de modo exequível e competente. Apesar de sua importância, para Matos e Barbosa (2021), a didática ainda é aindapercebida como método de ensino, não englobando a concepção de uma disciplina integradora que interliga diversis conhecimentos trazidos por diversas teorias do conhecimento, sendo a mesma reduzida a uma visão mais pragmática.

A Didática se ocupa do processo de ensino em diversas proporções, não se limitando exclusivamente à educação escolar, mas investiga e direciona a formação do educador na sua integralidade. É nesse contexto que Oliveira et al. (2021) apontam a necessidade de superar a visão tecnicista e instrumental que permeia as expectativas em torno desse componente curricular, e ao mesmo tempo viabilizar alternativas teórico metodológicas com uma essência mais freireana.

O fato de alguns estudantes $(22,2 \%)$ desse estudo considerarem a disciplina Didática pouco importante, pode estar relacionada ao desejo de não ser professor, observado na Figura 2, representando 32,1\% dos participantes. As indecisões e falta de motivação são fatores que podem levar a esses estudantes não considerarem essa disciplina como importante para a sua formação, pois quem realmente quer ser professor precisa da Didática. Nimitt e Pinto (2008) afirmam que a motivação é essencial para a profissão docente, tanto no processo de formação quanto no desempenho profissional, podendo interferir e influenciar a dinâmica de sua autodeterminação, expectativas e de sua percepção da eficácia e do alcance de objetivos pessoais. 
Posteriormente, questionou-se aos discentes quais das competências e habilidades da disciplina Didática presentes na ementa foram adquiridas pelos participantes da pesquisa após cursá-la. Dentre as competências e habilidades citadas, podemos destacar "elaborar e aplicar planos de ensino, observando seus elementos constitutivos" (20 participantes - 71,8 \%), "refletir sobre estratégias diversificadas de avaliação de aprendizagem e propostas de intervenção pedagógica que potencializem o desenvolvimento de diferentes capacidades nos alunos, reorientando o trabalho docente" (17 participantes - 60,7 \%), "compreender a função social do ensino e as concepções pedagógicas como referenciais para o desenvolvimento da prática pedagógica" (15 participantes - 53,6\%), e; "entender a gestão do trabalho docente tendo o planejamento como norteador das experiências educativas em sintonia com a natureza das instituições educativas e com as demandas sociais" (13 participantes $46,4 \%)$. Para a referida questão, os participantes podiam marcar mais de uma alternativa. Todas as competências e habilidades apontadas pelos discentes podem ser observadas no Quadro 1.

Quadro 1 - Representação das respostas dos participantes da pesquisa acerca das competências e habilidades que os mesmos adquiriram após cursarem a disciplina Didática.

\begin{tabular}{|l|c|}
\hline \multicolumn{1}{|c|}{ Competências e Habilidades } & $\begin{array}{c}\text { Frequência nas } \\
\text { respostas }\end{array}$ \\
\hline Elaborar e aplicar planos de ensino, observando seus elementos constitutivos. & $71,8 \%$ \\
\hline $\begin{array}{l}\text { Refletir sobre estratégias diversificadas de avaliação de aprendizagem e propostas de intervenção } \\
\text { pedagógica que potencialize o desenvolvimento de diferentes capacidades nos alunos, reorientando } \\
\text { o trabalho docente. }\end{array}$ & $60,7 \%$ \\
\hline $\begin{array}{l}\text { Compreender a função social do ensino e as concepções pedagógicas como referenciais para o } \\
\text { desenvolvimento da prática pedagógica. }\end{array}$ & $53,6 \%$ \\
\hline $\begin{array}{l}\text { Entender a gestão do trabalho docente tendo o planejamento como norteador das experiências } \\
\text { educativas em sintonia com a natureza das instituições educativas e com as demandas sociais. }\end{array}$ & $46,4 \%$ \\
\hline Identificar as concepções de currículo e suas implicações para o processo de ensino aprendizagem. & $32,1 \%$ \\
\hline $\begin{array}{l}\text { Conhecer os processos de organização e gestão do trabalho docente como norteadores de uma ação } \\
\text { intencional e sistemática. }\end{array}$ & $21,4 \%$ \\
\hline $\begin{array}{l}\text { Analisar, numa perspectiva crítica, a relevância dos conteúdos de ensino no processo de aquisição } \\
\text { do conhecimento. }\end{array}$ & $21,4 \%$ \\
\hline Não foi possível adquirir nenhuma dessas habilidades. & $10,7 \%$ \\
\hline
\end{tabular}

Fonte: Autores (2021).

Diante dos resultados supracitados, nota-se que a disciplina de modo geral foi bem conduzida, e os estudantes conseguiram adquirir diversas competências e habilidades, embora algumas tenham sido menos apontadas. Para Libâneo (1994), o processo teórico pedagógico conduz a atividade escolar por intermédio de objetivos, conteúdos e tarefas da formação cultural e científica, tendo em consideração exigências sociais concretas; no que lhe concerne, a ação educativa somente pode realizar-se através da atividade prática docente, da maneira que as situações didáticas concretas necessitem do "como" da intervenção pedagógica.

Em relação ao conhecimento dos processos de organização e gestão do trabalho, Libâneo (1994) relata que o trabalho do professor, articulado com uma atividade pedagógica do docente, vai ao encontro dos seguintes objetivos fundamentais:

\footnotetext{
"Assegurar aos alunos o domínio mais seguro e duradouro possível dos conhecimentos científicos; Criar condições e os meios para que os alunos desenvolvam capacidades e habilidades intelectuais de modo que dominem métodos de estudo e de trabalho intelectual visando a sua autonomia no processo de aprendizagem e independência de pensamento; Orientar as tarefas de ensino para objetivos educativos de formação da personalidade, isto é, ajudar os alunos a escolherem um caminho na vida, a terem atitudes e convicções que norteiem suas opções diante dos problemas e situação da vida real (Libâneo, 1994, p. 71).”
}

Portanto, percebe-se a necessidade de se organizar e planejar profissionalmente para que haja um bom desenvolvimento do trabalho docente; além disso, vale destacar que os conhecimentos são adquiridos a partir do diálogo e experiências com pessoas dos diferentes convívios sociais, sendo o desenvolvimento de habilidades fundamental para 
fortalecer e assegurar a aprendizagem. Para Libâneo et al. (2012), no seu planejamento, o docente deve possuir clareza em seus objetivos e conteúdo, e devem conseguir cativar os alunos, e além disso, devem utilizar metodologias e procedimentos adequados à matéria e as condições de aprendizagens dos alunos.

Posteriormente, questionou-se os discentes sobre as competências e habilidades da disciplina Didática mais difíceis de serem obtidas. Nas respostas, os participantes apontaram: "refletir sobre estratégias diversificadas de avaliação de aprendizagem e propostas de intervenção pedagógica que potencializem o desenvolvimento de diferentes capacidades nos alunos, reorientando o trabalho docente" (oito participantes - 28,6 \%), "identificar as concepções de currículo e suas implicações para o processo de ensino aprendizagem e analisar, numa perspectiva crítica, a relevância dos conteúdos de ensino no processo de aquisição do conhecimento" (sete participantes - 25 \%) e "analisar, numa perspectiva crítica, a relevância dos conteúdos de ensino no processo de aquisição do conhecimento" (sete participantes $-25 \%$ ). As respostas estão apresentadas no Quadro 2.

Quadro 2 - Representação das respostas dos participantes da pesquisa sobre quais competências e habilidades da disciplina de didática, que os participantes tiveram as principais dificuldades ao cursar a disciplina.

\begin{tabular}{|l|c|}
\hline \multicolumn{1}{|c|}{ Competências } & $\begin{array}{c}\text { Frequência nas } \\
\text { respostas }\end{array}$ \\
\hline $\begin{array}{l}\text { Refletir sobre estratégias diversificadas de avaliação de aprendizagem e propostas de intervenção } \\
\text { pedagógica que potencialize o desenvolvimento de diferentes capacidades nos alunos, reorientando } \\
\text { o trabalho docente. }\end{array}$ & $28,6 \%$ \\
\hline Identificar as concepções de currículo e suas implicações para o processo de ensino aprendizagem. & $25 \%$ \\
\hline $\begin{array}{l}\text { Analisar, numa perspectiva crítica, a relevância dos conteúdos de ensino no processo de aquisição } \\
\text { do conhecimento. }\end{array}$ & $25 \%$ \\
\hline Não senti nenhuma dificuldade ao cursar a disciplina Didática. & $21,4 \%$ \\
\hline $\begin{array}{l}\text { Conhecer os processos de organização e gestão do trabalho docente como norteadores de uma ação } \\
\text { intencional e sistemática. }\end{array}$ & $21,4 \%$ \\
\hline Elaborar e aplicar planos de ensino, observando seus elementos constitutivos. & $17,9 \%$ \\
\hline $\begin{array}{l}\text { Entender a gestão do trabalho docente tendo o planejamento como norteador das experiências } \\
\text { educativas em sintonia com a natureza das instituições educativas e com as demandas sociais. }\end{array}$ & $14,3 \%$ \\
\hline $\begin{array}{l}\text { Compreender a função social do ensino e as concepções pedagógicas como referenciais para o } \\
\text { desenvolvimento da prática pedagógica. }\end{array}$ & $3,6 \%$ \\
\hline
\end{tabular}

Fonte: Autores (2021).

Para Vieira e Martins (2009), a Didática possui um papel indispensável nos cursos de licenciaturas, orientando o discente à prática pedagógica reflexiva e coordenando os pontos principais do processo de ensino-aprendizagem, que deverão ir ao encontro do que está ocorrendo além dos muros das Instituições de Ensino Superior, impactando no sistema educacional brasileiro. Dessa forma, consideramos indispensável a apropriação das diversas competências e habilidades pelos licenciandos no cursar da disciplina Didática, uma vez que os desafios impostos pelo sistema educacional exigem do professor a frequente utilização de tais aprendizados.

Quando questionados acerca da carga horária da disciplina de Didática no curso de Licenciatura em Ciências Biológicas, considerando os parâmetros "suficiente, deixa a desejar ou excede o necessário", a maior parte (18 participantes $64,3 \%)$ afirmaram que a carga horária foi suficiente, oito participantes $(28,6 \%)$ responderam que a carga horária da disciplina deixa a desejar, e dois participantes $(7,1 \%)$ responderam que a carga horária da disciplina excede o necessário, conforme observado na Figura 5. 
Figura 5 - Opinião dos discentes em relação à carga horária destinada à disciplina Didática no curso de Licenciatura em Ciências Biológicas.

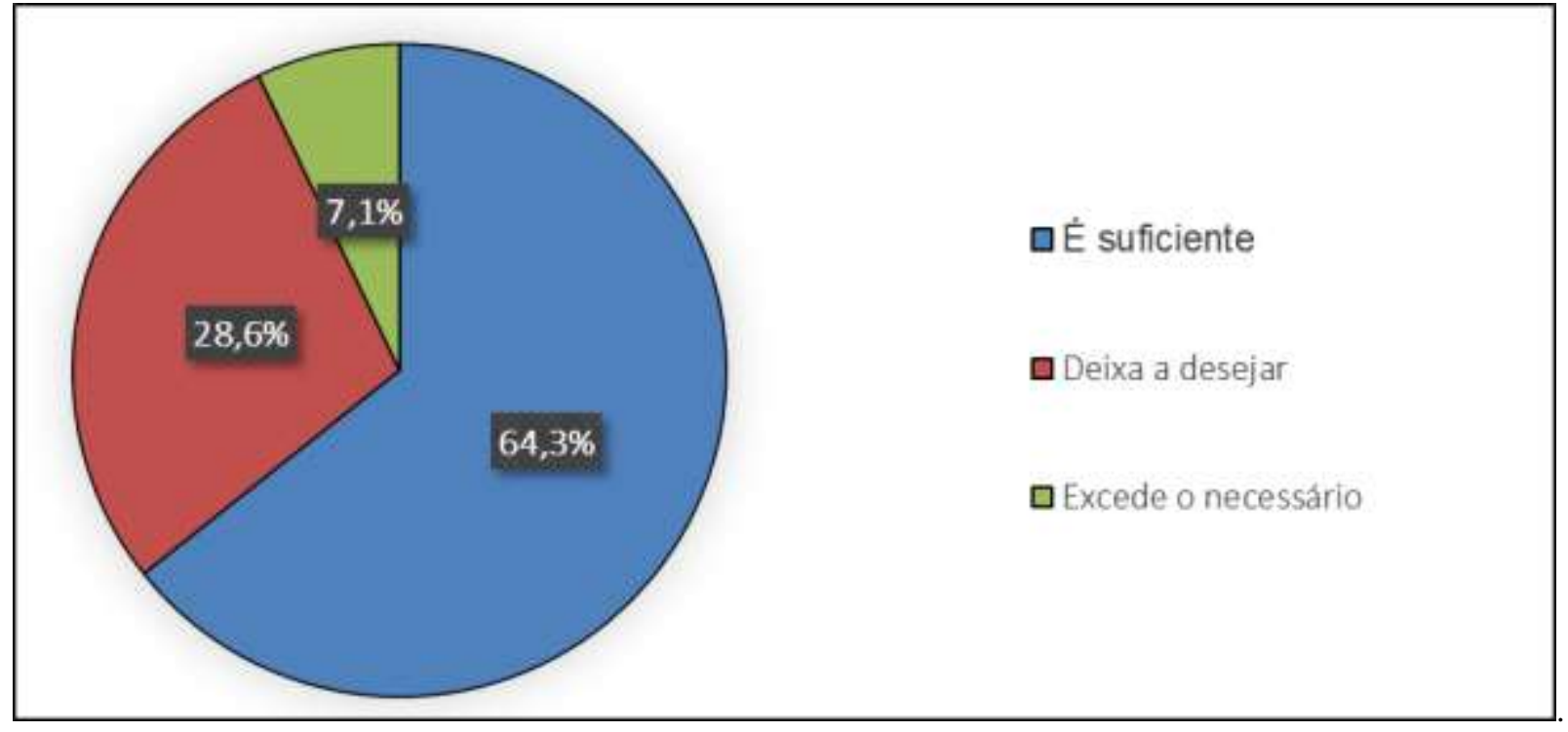

Fonte: Autores (2021).

Gatti (2014), relata que os cursos de licenciatura empregam uma carga horária bem reduzida de seus currículos às disciplinas pedagógicas, direcionando o foco mais aos conhecimentos específicos; com isso, observa-se uma formação docente precária para os anos finais do ensino fundamental e para o ensino médio. Dessa forma, percebe-se a importância de um melhor planejamento na distribuição da carga horária das disciplinas pedagógicas: por ser deveras importante na formação docente, apontamos que a Didática deve ser vista como prioridades na distribuição das cargas horárias.

$\mathrm{Na}$ oitava questão, os discentes foram perguntados acerca das mudanças metodológicas que fariam na disciplina Didática, caso fossem o (a) professor (a) da referida disciplina. A maioria dos participantes (21 - $75 \%)$ respondeu que não fariam modificações na disciplina. Sete participantes (25\%) mudariam a forma de ministrar as aulas da disciplina Didática. Os alunos que desejariam mudança na disciplina foram questionados sobre que mudanças seriam essas; as respostas dos mesmos podem ser observadas no Quadro 3.

Quadro 3 - Representação das respostas dos participantes em relação às mudanças que fariam, caso fossem professores da disciplina Didática.

\begin{tabular}{|l|l|}
\hline \multicolumn{1}{|c|}{ ALUNO (A) } & \multicolumn{1}{c|}{ MUDANÇA METODOLÓGICA QUE FARIAM } \\
\hline Aluno A & "Instigar os discentes a novas habilidades educacionais úteis" \\
\hline Aluno B & "Métodos variados que auxiliem na prática a didática do educador" \\
\hline Aluno C & $\begin{array}{l}\text { "Cada professora tem seus métodos frente a realização de suas aulas. Então consequentemente eu } \\
\text { também teria outras metodologias de ensino." }\end{array}$ \\
\hline Aluno D & "Ampliaria os debates." \\
\hline Aluno E & "A carga horária" \\
\hline Aluno F & "Ensinaria as estratégicas metodológicas de como elaborar modelos didáticos...” \\
\hline
\end{tabular}

Fonte: Autores (2021).

Para Matos e Barbosa (2021), a formação do docente da disciplina Didática deve ser capaz de contemplar a relação entre teoria e prática de uma maneira reflexiva e crítica, considerando as peculiaridades de cada contexto social. Os autores destacam ainda, a importância da práxis durante a formação docente, pois é quando o professor se apropria do seu fazer de forma crítica que ele irá desenvolver uma prática educativa transformadora. Ou seja, é necessário que o docente conheça a realidade do ambiente inserido para aplicar as metodologias adequadas para o ensino e aprendizagem dos alunos. 
Ao serem questionados acerca da principal motivação para cursar a disciplina Didática, os discentes responderam que era "conhecer novas metodologias para me guiar em sala de aula" (18 participantes - 64,3 \%), "criar novas habilidades fundamentais para a minha formação" (nove participantes - 32,1\%) e "aprimorar metodologias que já conheço" (um participante - 3,6 \%); nenhum discente optou pela motivação "estimular em mim a vontade de ser professor", como observado na Figura 6.

Figura 6 - Respostas dos participantes sobre a principal motivação dos mesmos para cursar a disciplina Didática.

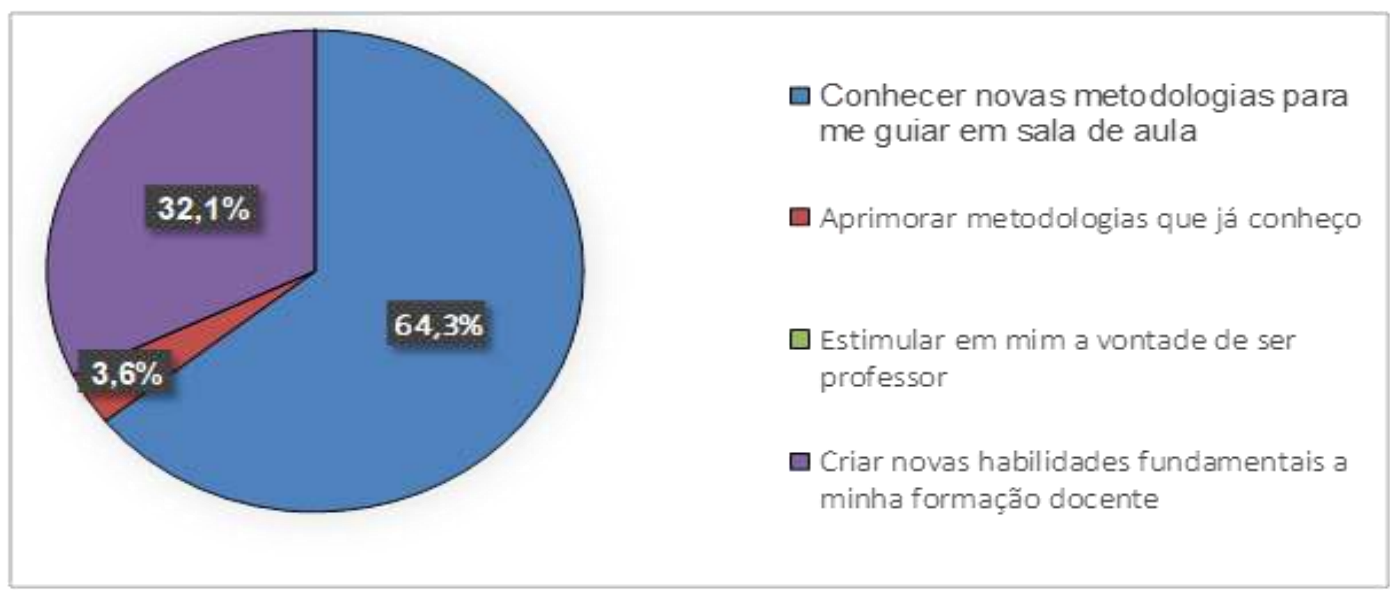

Fonte: Autores (2021).

Em relação ao questionamento feito anteriormente, perguntou-se aos discentes se tal motivação foi alcançada. Nas respostas, 20 participantes $(71,4 \%)$ afirmaram que sim, e oito participantes $(28,6 \%)$ afirmaram que não. Manter a motivação é necessário para o desenvolvimento de qualquer atividade, e na educação não é diferente. Nessa perspectiva, Meireles (2015), destaca a importância de se conhecer as questões de grande relevância no processo da prática docente correlacionando a motivação humana, que interferem na relação professor-aluno e, consequentemente, no processo de ensino-aprendizagem. Ou seja, a partir do momento que tivermos docentes bem preparados, teremos também docentes mais motivados.

\section{Considerações Finais}

Diante dos resultados apresentados neste estudo, apontamos que muitos estudantes entram nos cursos de licenciaturas por falta de oportunidade em ingressar outro curso desejado, que tem como principal motivo o cenário educacional brasileiro, onde os professores são desvalorizados, desassistidos e desrespeitados. Portanto, a valorização do professor exige esforços de todo o sistema educacional e é um ponto fundamental para o estímulo à formação de novos professores, com profissionais de excelência e cada vez mais capacitados para exercer a atividade docente.

Nossos dados também demonstram que a maior parte dos participantes consideram a disciplina Didática importante na formação docente, e que esta deve ser ministrada de maneira a contribuir na preparação do futuro professor para atuar com êxito em sala de aula. Em relação às competências e habilidades que são propostas para a disciplina de Didática, segundo a maioria dos estudantes, esses foram alcandas. Frente a importância na apropriação dessas habilidades e competências, apontamos que a disciplina deve passar por uma análise da carga horária e que permita participação de todos os alunos.

Por fim, relatamos que a maior motivação dos graduandos em cursar a disciplina Didática foi a de conhecer novas metodologias para serem utilizadas em sala de aula no seu fazer docente. Dessa forma, é importante se aproveitar desse interesse e motivação dos discentes, e a partir disso apresentar e estimular o uso de metodologias diversas no contexto escolar, que permitam assim maior suporte ao docente em formação, para este esteja preparado à diversidade de discentes que 
encontrará em sala de aula. Apontamos também a necessidade de realização de outros estudos, inclusive com professores que atuam na educação básica, avaliando também a importância da disciplina no contexto escolar desses docentes.

\section{Referências}

Bastos, M. J. (2017). A Importância da Didática na Formação Docente. Revista Científica Multidisciplinar Núcleo do Conhecimento, 01(14), 64-70.

Batista, I. A., Medrado, M. M. M., \& Costa, R. J. (2018). A importância das disciplinas pedagógicas na formação dos licenciandos de ciências biológicas do IFTO - Campus Araguatins. Jornada de iniciação científica e extensão JiCE. https://propi.ifto.edu.br/index.php/jice/9jice/paper/viewFile/9265/4222.

Cerqueira, S. V. S., \& Cardoso, L. R. (2010). Biólogo-professor: relação entre expectativas profissionais e concepções em torno da docência para licenciandos em Ciências Biológicas. Revista Contexto e Amp; Educação, 84, 143-160.

Faustino, E. M. B., Silva, A. C. O., \& Rodrigues, E. C. (2013). Problemas enfrentados pelos docentes em sala de aula. XI Congresso Nacional de Educação, Pontifícia Universidade Católica do Paraná. https://educere.bruc.com.br/ANAIS2013/pdf/9447_6834.pdf.

Fernandes, C. L., Soares Neto, J. G., Nascimento, P. H. L., \& Oliveira, M. J. (2016). O impacto da desvalorização da licenciatura na formação de professores na área de Química. In: Congresso Nacional de Educação, 3. file://C:/Users/leand/Downloads/TRABALHO_EV056_MD1_SA4_ID102 55_15082016 185015.pdf.

Ferreira, M., \& Loguecio, R. Q. (2014). A análise de conteúdo como estratégia de pesquisa interpretativa em educação em ciências. Revista de Educação, Linguagem e Literatura, 6(2), 33-49.

Fonseca Matos, E. O., \& de Sousa Barbosa, C. H. (2021). As contribuições da Disciplina de Didática para a Formação Docente. Ensino em Perspectivas, 2(1), $1-10$.

Fontelles, M. J., Simões, M. G., Farias, S. H., \& Fontelles, R. G. S. (2009). Metodologia da Pesquisa Científica: diretrizes para a elaboração de um protocolo de pesquisa. Revista paraense de medicinam, 23(3), 1-8.

Gatti, B. A. (2014). A formação inicial de professores para a Educação Básica: as licenciaturas. Revista USP, 100(1), 33-46.

Gonçalves, R. M. G., \& Rochael, M. C. N. (2015). A importância da didática para a formação do docente do ensino superior. Revista Científic@ Universitas, $3(1)$.

Henrique, A. L. S., \& Nascimento, J. M. (2015). Sobre práticas integradoras: um estudo de ações pedagógicas na educação básica. Holos, 31(4), 63-76.

Libâneo, J. C. Didática. (1994). Cortez.

Libâneo. J. C. Didática. (2017). São Paulo: Cortez. https://books.google.com.br/books?hl=pt-BR\&lr=\&id=q3MzDwAAQBAJ\&oi=fnd\&pg $=\mathrm{PT} 3 \& \mathrm{dq}=\mathrm{did} \% \mathrm{C} 3 \%$ A1tica\&ots=bUWSmBvB8f\&sig=sRJdas4g6ofiLVq3BkebT1RxADg\#v=onepage\&q=did\%C3\%A1tica\&f=false.

Libâneo, J. C., Oliveira, J. F., \& Toschi, M. S. (2012). Educação escolar: políticas, estrutura e organização. (10. ed.). Cortez.

Ludke, M., \& Andre, M. E. D. A. (2013). Pesquisas em educação: uma abordagem qualitativa. E.P.U.E.

Matos, E. O. F., \& Barbosa, C. H. S. (2021). As contribuições da Disciplina de Didática para a Formação Docente. Ensino em Perspectivas, 2(1), 1-10.

Meireles, C. D. (2015). O papel da motivação na prática docente. Universidade Federal da Paraíba. https://repositorio.ufpb.br/jspui/bitstream/1234 56789/296 6/1/CDM06042015.pdf.

Milam, G. A. (2017). Percepção dos concluintes do curso de Licenciatura em Ciências Biológicas da UFPB sobre o curso e atividade profissional. 60f. http://www.ccen.ufpb.br/cccb/contents/monografias/monografias-2017/gessica-alves-milam.pdf.

Mota, J. S. (2019). Utilização do Google forms na pesquisa acadêmica. Revista Humanidades e Inovação, 6 (12), 371 -390.

Nimitt, D. B., \& Pinto, C. B. G. C. (2008). Formação em Pedagogia: expectativas e motivação ligadas à prática pedagógica do professor. Universitas Humanas, 5 (1), 159-180.

Oliveira, R. L., Barra, T. B. A., \& de Albuquerque Figueiredo, J. B. (2021). A didática em diálogo com a pedagogia freireana. Ensino em Perspectivas, 2(4), 112.

Ribeiro, J. L. S., Silva, L. G., \& Teixeira, A. L. (2018). A importância da didática na formação docente. $3^{\circ}$ ELPED E $4^{o}$ encontro de licenciaturas e do PIBID do sudoeste goiano (ELICPIBID). https://www.ifgoiano.edu.br/periodicos/index.php/ciclo/article/view/703/535.

Ribeiro, R. R. R. P. C., Monteiro, R. R. M., \& Junior, A. G. M. (2017). Docência universitária no curso de licenciatura em letras: relação entre saberes, formação e disciplinas pedagógicas. Revista Expressão Católica, 6(2), 32-39.

Simião, L. F., \& Reali, A. M. M. R. (2002). O uso do computador, conhecimento para o ensino e aprendizagem profissional da docência. In: Mizukami, M. G. N.; Reali, A. M. M. R. (Orgs.). Formação de professores, práticas pedagógicas e escola, 1(1), 127-149.

Silva, R. C. (2019). Aprenda Sobre a Influência da Didática na Formação Docente. Blog Maxi educa. https://blog.maxieduca.com.br/didatica-formacaodocente/. 
Research, Society and Development, v. 11, n. 2, e6311225346, 2022

(CC BY 4.0) | ISSN 2525-3409 | DOI: http://dx.doi.org/10.33448/rsd-v11i2.25346

Trez, M. A. W. (2016). A disciplina Didática nos cursos de licenciatura em Ciências Biológicas. https://spo.ifsp.edu.br/images/phocadownload/DOCUMENTOS_MENU_LATERAL_FIXO/POS_GRADUA\%C3\%87\%C3\%83O/ESPECIALIZA\%C3\%87\% C3\%83O/Forma\%C3\%A7\%C3\%A3o_de_Professores_\%C3\%8Anfase_Ensino_Superior/Produ\%C3\%A7\%C3\%B5es/2016/Maria_Angelica_Wolochyn_Trez. pdf.

Vieira, D. C. O., \& Martins, P. L. O. (2009). As disciplinas de didática nos cursos de licenciaturas. IX Congresso Nacional de Educação - Enducere, III Encontro Sul Brasileiro de Psicologia. 1-9. https://educere.bruc.com.br/cd2009/pdf/2027_2186.pdf. 